\title{
High-speed thermal-cycle processing of low-carbon steel in the initially hardened and initially cold-deformed condition
}

\author{
Dmitry Olegovich Panov ${ }^{a^{*}}$, Alexander Igorevich Smirnov ${ }^{b}$ and Yury Nikolaevich Simonov
}

${ }^{a}$ Perm National Research Polytechnic University, Komsomolsky prospect, 29, Perm, 614990, Russia ${ }^{b}$ Novosibirsk State Technical University, K. Marksa prosp., 20, Novosibirsk, 630073, Russia

\begin{tabular}{l}
\hline A R T I C L E I N F O \\
\hline Article history: \\
Received 6 October, 2015 \\
Accepted 27 January 2016 \\
Available online \\
27 January 2016 \\
\hline Keywords: \\
Low carbon steel \\
Thermal-cycle processing \\
Austenitization \\
Massive martensite \\
Dilatometry
\end{tabular}

\section{Introduction}

Most modern methods of increasing of materials strength are based on realization of a number of non-equilibrium conditions amorphous condition, high stress level of the first, second or third kind (Kaputkin, 2007). Such conditions are reached in the process of mechanical or thermal impact, as well as in combination of these operations. Recently, much attention of researchers was paid to the problems of materials with ultra-fine grain and nanocrystalline structure, which were obtained by method of severe plastic deformation (SPD): severe plastic deformation by torsion under high pressure, equal channel angular pressing (ECAP), extrusion, comprehensive rotary forging and others. The basic of the basic methods of SPD is ECAP, which was developed by Segal (1997) and subsequently was extended more by Valiev (2006). This method enables, without final formation of a preform, to create therein a high degree of plastic deformation that results in metal ultra-fine grain materials. However, this method

\footnotetext{
* Corresponding author

E-mail addresses: t.ablyaz@mail.ru (D. O. Panov) 
makes it possible to obtain preforms of relatively small size. Cold plastic deformation of structural steels causes an increase in the dislocations concentration and the formation of additional subboundaries in the evolution and self-organization of the dislocation subsystem, which increases the degree of non-equilibrium initial condition. Cold plastic deformation of structural steels with high degrees of deformation should be performed using methods providing the softest scheme of loading and deformation, which will allow a high degree of deformation without destruction. In this regard the advanced way to implement cold plastic deformation is a method of radial forging, which makes it possible to obtain the preforms on an industrial scale. A characteristic property of this deformation method is the force applied simultaneously by several radially moving panes, at which the soft loading scheme is realized - the scheme of uneven all-around compression (Tyurin et al. 1990).

To obtain the structural condition of a material having both a high level of strength and reliability for highly responsible constructions and details, it is necessary to use constructional low-carbon steels of 10H3G3MF type systematically alloyed. To provide high levels of reliability, along with a high level of strength characteristics of these steel it is necessary to consistently obtain the following structural conditions in constructional steels, i.e. to implement the following steps of dispersing structure:

- Hardened condition of nonstructural low-carbon systematically alloyed steels with a structure of massive martensite with high defectiveness, which is characterized by good technological plasticity (Kurdiumov 1977).

- Highly defective condition of nonstructural steels resulting from the evolution of the dislocation structure at cold plastic deformation.

- Condition of the recrystallized austenite of initially cold-deformed structural steel, formed in the primary recrystallization. Such condition can be obtained by quick short austenitization of the steel, subject to inheritance by austenite of high dislocations concentration in the temperature separation of processes of phase and structural recrystallization or the formation of a large number of germs of austenite while heating in the inter-critical temperature range with the simultaneous running of phase and structural recrystallization processes (Sadowski 1973).

Finely dispersed hardened condition, which is formed as a result of the martensitic transformation in recrystallized austenite upon cooling and repetitive cyclic heating can lead to additional dispersion of the structure (Du et al. 2009), and as a consequence to increase in the level of mechanical properties. Thus, the purpose of this article is to study the processes of formation of structure and properties of systemically alloyed low carbon steel 10H3G3MF at high speed thermal-cycle processing.

\section{Method}

As a material for study here is selected the steel $10 \mathrm{H} 3 \mathrm{G} 3 \mathrm{MF}$ of the following chemical composition: mass. \%: 0,1 \% C, 0,34 \% Si, 2,81\% Mn, 2,77\% Cr, 0,40\% Mo, 0,12\% V, 0,002\% Ti, $0,009 \% \mathrm{~S}, 0,020 \% \mathrm{P}$ (Simonov et al. 2013). High speed TCP at the temperature of 900 and $1000^{\circ} \mathrm{C}$ with a heating rate of about $90{ }^{\circ} \mathrm{C} / \mathrm{c}$ was carried out in molten salt using salt-bath furnace excerpt 35 and with after cooling in water. Number of heating and cooling cycles while processing was ranged from 1 to 5.

Initially hardened condition of the analyzed steel was obtained by hardening in the air with the hot forging temperature. To obtain initially cold-deformed condition the analyzed steel in the hardened condition was exposed to cold radial forging with a degree of $60 \%$. Metallographic analysis was carried out on micro-sections using optical inverted microscope OLYMPUS GX 51 with up to 1000-fold magnifications. The images were processed using the SIAMS 700 hardware-software complex for image analysis, as well as using the OLYMPUS Stream Motion software. 
Dilatometric analysis of the processes of phase transformations at high speed TCP at $900{ }^{\circ} \mathrm{C}$ in steel $10 \mathrm{H} 3 \mathrm{G} 3 \mathrm{MF}$ in initially hardened and initially cold-deformed condition was carried out using a hardening dilatometer Linseis RITA L78 at heating with a rate of $90^{\circ} \mathrm{C} / \mathrm{s}$. Cooling was performed at a rate of $50{ }^{\circ} \mathrm{C} / \mathrm{s}$, which provided the implementation of the martensitic transformation in each processing cycle. To determine the temperature of the analyzed sample a K-type thermocouple (Ni$\mathrm{NiCr}$ ), which was welded to the side surface of the sample, was used. Heating was performed in an inert atmosphere of gaseous helium of $99.9999 \%$ purity. Electron microscopic studies of the fine structure were performed on thin foils using a transmission electron microscope FEI Tecnai G2 TWIN 20 at an accelerating voltage of $200 \mathrm{kV}$. Uniaxial tensile test was carried out on a universal hydraulic system for static tests INSTRON-SATEC 300 LX. Calculation of strength characteristics $\left(\sigma_{\mathrm{B}}, \sigma_{0,2}\right)$ and plasticity $(\delta, \psi)$ was carried out in accordance with the requirements of GOST 1497-84 on five-fold cylindrical samples of the III no. 7 type. Test for evaluating the toughness of FTC were performed at room temperature on a pendulum PSWO- 30 samples of type 17 in accordance with GOST 9454-78.

Micro-fractographic analysis was performed using scanning electron microscopes Phenom ProX and Carl Zeiss EVO50 in the central part of fractures near the fatigue crack where the crack spread when tested under conditions of plane-strain deformation.

\section{Results and discussion}

\subsection{Analysis of microstructural evolution}

Metallographic analysis of 10H3G3MF steel after different modes of high-speed TCP at 900 and $1000{ }^{\circ} \mathrm{C}$ was performed to analyze the evolution of austenite grain structure during processing in the molten salt. Fig. 1 graphically presents the dynamics of the austenite average grain size change of the analyzed steel after different modes of high-speed TCP at 900 and $1000{ }^{\circ} \mathrm{C}$ in the initially hardened (Fig.1a) and initially cold-deformed (Fig.1b) condition.
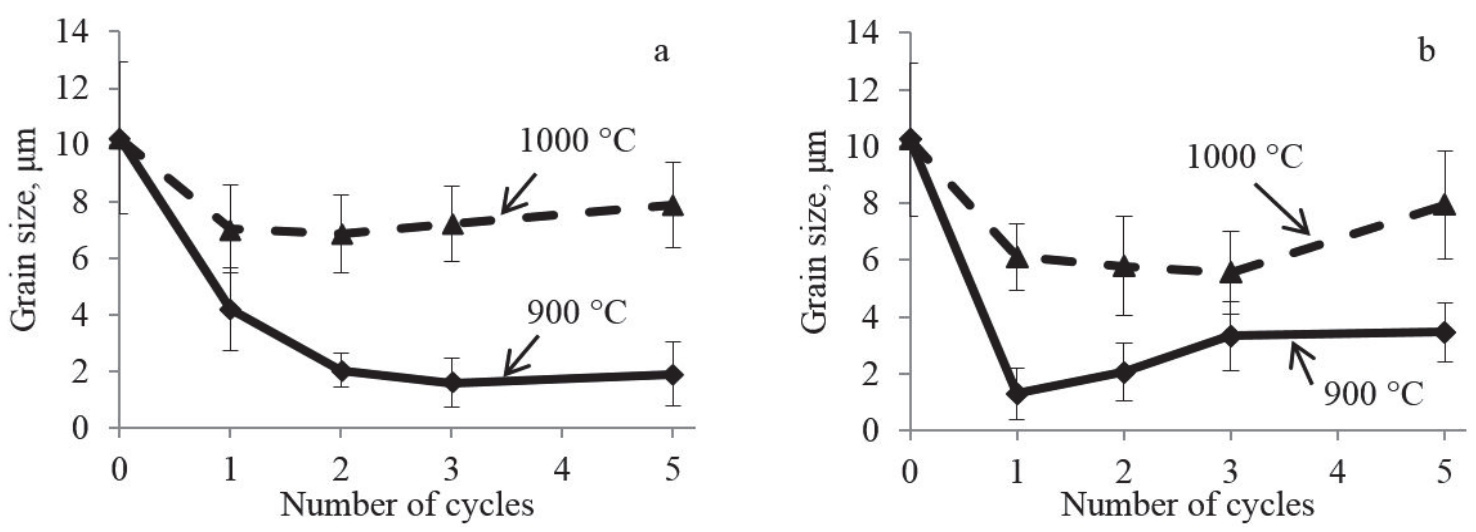

Fig.1. Dependence of the average size of austenite grain of the steel 10H3G3MF in initially hardened (a) and initially cold-deformed condition (b) on the number of cycles of the high speed TCP in molten salt at temperatures of 900 and $1000{ }^{\circ} \mathrm{C}$. Note: a zero cycle refers to the initial condition, where the grain size is $10 \mu \mathrm{m}$.

For the case of high speed TCP at $900{ }^{\circ} \mathrm{C}$ of initially hardened steel $10 \mathrm{H} 3 \mathrm{G} 3 \mathrm{MF}$ fine crushing of austenite structure goes up to the third cycle, when the austenite grain size is $2 \mu \mathrm{m}$, when the number of cycles is increased, the austenite grain size does not change substantially (Fig. 1a). In the first cycle of the high speed TCP at $1000{ }^{\circ} \mathrm{C}$ austenite grain is crushed to $7 \mu \mathrm{m}$, and further TCP does not lead to a significant change in the average grain size, which is due to more intensive development of the processes of accumulative recrystallization of austenite at $1000^{\circ} \mathrm{C}$ than at $900{ }^{\circ} \mathrm{C}$ (Lee \& Lee, 2008). 
At high speed TCP at $900{ }^{\circ} \mathrm{C}$ at cold-deformed steel 10H3G3MF the most dispersed austenite structure is observed after the first cycle of processing, at the same time the average grain size is crushed to $1 \mu \mathrm{m}$ (Fig.1b). If at $900{ }^{\circ} \mathrm{C}$ the number of cycles is increased further to the third one, the average austenite grain size hardened to $3.5 \mu \mathrm{m}$, and at the following processing cycles at $900{ }^{\circ} \mathrm{C}$ the austenite size remains practically unchanged. The observed dynamics of changes in the structure of austenite grains is provided by the evolution of the structure of defects at high-speed TCP of initially colddeformed steel. Thus, when the first rapid heating in the inter-critical temperature range in high defective $\alpha$-matrix, a large number of austenite germs is formed, which makes it possible to obtain ultrafine-grain condition of austenite at the moment of austenitization completion. During the second cycle massive martensite structure is exposed to heating, which probably leads to the formation of less number of germs of austenite and a greater size of grains (Panov et al. 2012). Beginning with the third cycle a stabilization of the average austenite grain size at high speed TCP at $900{ }^{\circ} \mathrm{C}$ is observed. High speed TCP at $1000{ }^{\circ} \mathrm{C}$ in the first heating cycle causes fine crushing of austenite grain to $6 \mu \mathrm{m}$, but increase of the number of processing cycles at this temperature leads to further dispersion of the structure (Fig. 1b).

\subsection{Electron microscope investigation}

The fine structure of steel $10 \mathrm{H} 3 \mathrm{G} 3 \mathrm{MF}$ after high speed TCP at $900{ }^{\circ} \mathrm{C}$ in initially hardened and initially cold-deformed condition was studied using the method of transmission electron microscopy. Fig. 2 presents the results of the study of the fine structure of steel 10H3G3MF in most states dispersed conditions of austenite after studied modes of processing. Using electron microscopic studies of initially hardened steel $10 \mathrm{H} 3 \mathrm{G} 3 \mathrm{MF}$ after 3 cycles of high-speed TCP at $900{ }^{\circ} \mathrm{C}$ it was established that the single-massive martensitic areas with a high dislocations concentration inside formed within the former austenite grain are observed in the structure (Fig.2a). At the same time the average cross sectional dimensions of the martensite laths is (120 \pm 10$) \mathrm{nm}$ (Fig. 2b).
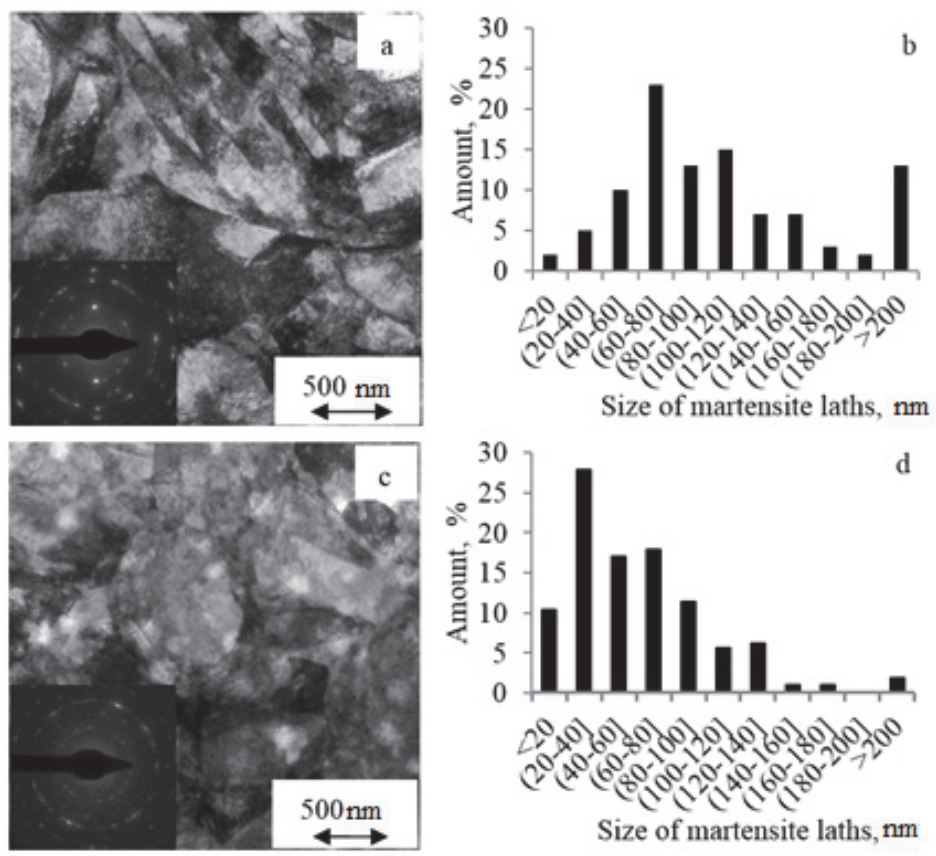

Fig. 2. Fine structure $(\mathrm{a}, \mathrm{c})$ and the histogram of distribution of the average cross sectional dimension of the martensite stick determined in the plane of the foil $(b, d)$ after the high speed TCP at $900{ }^{\circ} \mathrm{C}, 3$ cycles of steel $10 \mathrm{H} 3 \mathrm{G} 3 \mathrm{MF}$ in the initially hardened condition, after 1 cycle of heating up to $900{ }^{\circ} \mathrm{C}$ of the steel $10 \mathrm{H} 3 \mathrm{G} 3 \mathrm{MF}$ in the initially cold-deformed condition 
Fine structure of the initially cold-deformed steel 10H3G3MF after 1 cycle of high speed TCP at $900{ }^{\circ} \mathrm{C}$ (Fig. 2c) also consists of spherical areas of the former austenite grains, the average size of which corresponds to the average grain size according to metallographic analysis data, inside of which a massive martensite structure is formed as a result of the martensite transformation. Micro-diffraction image is an annular diffraction, indicating a large number of crystallographic orientations in a given volume (Fig. 2c). The average size of the martensite stick (Fig. 2d) is $(60 \pm 10) \mathrm{nm}$, and the distribution of the sticks according to the size has unimodal character.

\subsection{Dilatometric analysis of the $\alpha \rightarrow \gamma$-transformation}

Dilatometric curves of heating and first derivatives dilatometric curves at high speed TCP at 900 ${ }^{\circ} \mathrm{C}$ of steel $10 \mathrm{H} 3 \mathrm{G} 3 \mathrm{MF}$ in initially hardened and initially cold-deformed condition are shown in Fig. 3.
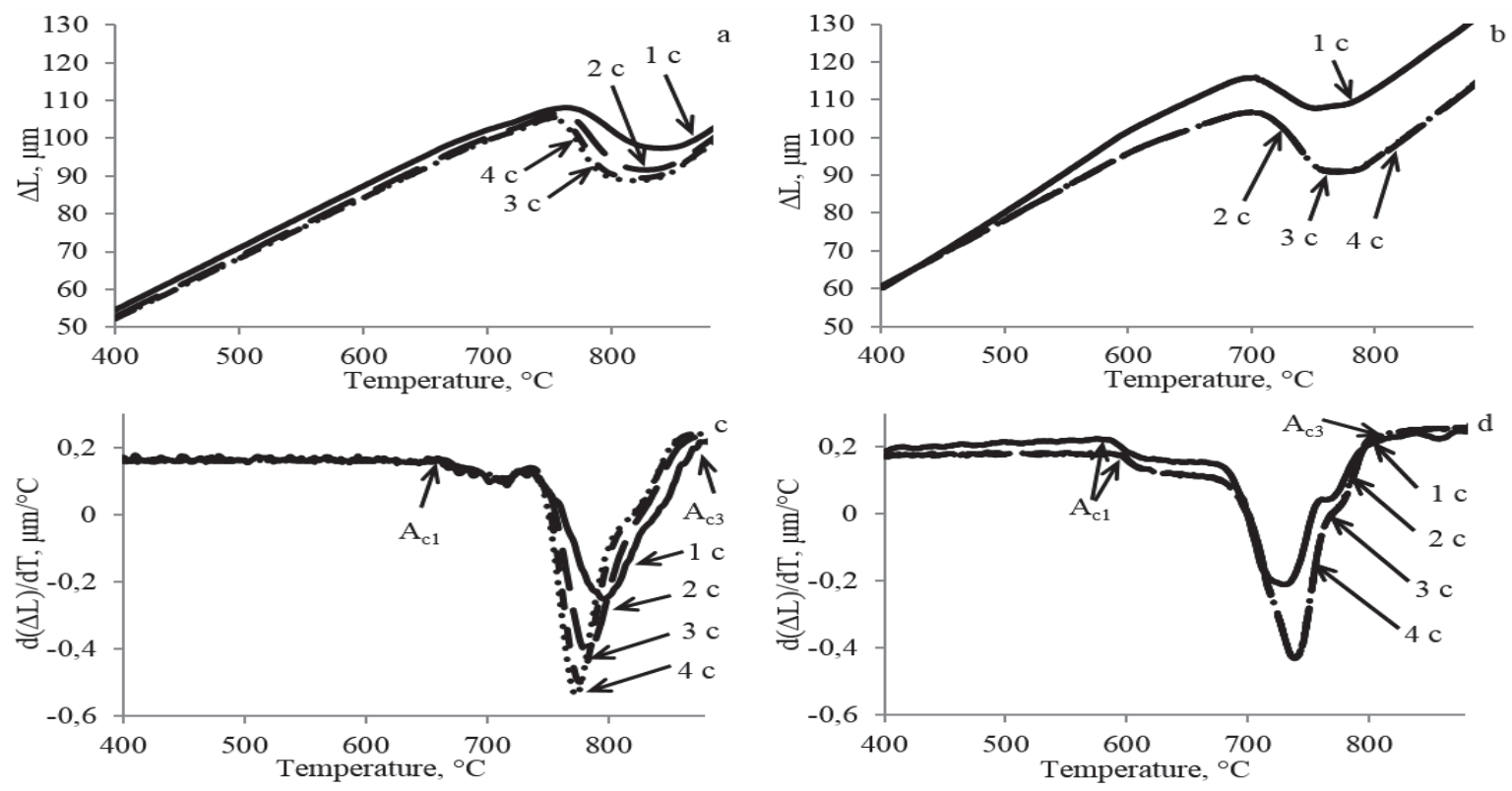

Fig.3. Dilatometric curves of heating $(a, b)$ and the first derivatives of the dilatometric curves (c, d) of steel 10H3G3MF in initially hardened condition $(\mathrm{a}, \mathrm{c})$ and cold-deformed $(\mathrm{b}, \mathrm{d})$ condition obtained during high speed TCP at $900{ }^{\circ} \mathrm{C}$ with a heating rate of $90{ }^{\circ} \mathrm{C} / \mathrm{c}$

During high-speed TCP of steel 10H3G3MF TCI in initially hardened condition dilatometric curve of the first heating cycle at $90^{\circ} \mathrm{C} / \mathrm{s}$ is located above along the axis of the absolute elongation, and when the number of cycles is increased further, the dilatometric curves fall down (Fig. 3a), which is caused by the intensification of processes of phase transformations as a result of dispersing of a steel structure. Dependency relations of the first derivative of the dilatometric curve with increase of the number of cycles of the TCP to a temperature $A_{\mathrm{C} 1}$ remains at the same level, and from cycle to cycle the value of the maximum in the area of $\alpha \rightarrow \gamma$-transformation in modulus increases (Fig. 3c), indicating a higher rate of occurring processes.

During high speed TCP of the analyzed steel in the initially cold-deformed condition at the first cycle the dilatometric curve (Fig. 3b) is located above along the axis of the absolute elongation. At the following heating cycles the position of the dilatometric curves is below along the absolute elongation axis, and they are practically coincide, i.e. superimpose on one another. The following tendency is observed on the dependency relations of the first derivative of dilatometric curve - at the first heating cycle the value of the first derivative exceeds the values of the first derivative at the following cycles of heating, and the curves of the second, third and fourth cycles are practically the same, i.e. the value 
of the peak maximum on the first derivative in ITR on the second cycle increases and slightly changes in the following cycles (Fig. 3d). Such change of the dilatometric curves and derivatives from them during the high speed TCP at $900{ }^{\circ} \mathrm{C}$ of steel $10 \mathrm{H} 3 \mathrm{G} 3 \mathrm{MF}$ in initially cold-deformed condition is provided by the fact that at the first cycle the highly defective condition is subjected to heating which leads to a higher intensity of the $\alpha \rightarrow \gamma$-transformation. As a result a dispersed structure of massive martensite, which is exposed to heating in the second cycle of high speed TCP at $900{ }^{\circ} \mathrm{C}$, is formed at the first cycle, which leads to the intensification of the $\alpha \rightarrow \gamma$-transformation.

As a result of analysis of dilatometric curves using the lever method (Gladstein et al. 2008) there were constructed kinetic curves of austenite formation at a heating to $900^{\circ} \mathrm{C}$ at a different number of cycles of high speed TCP (Fig. 4).
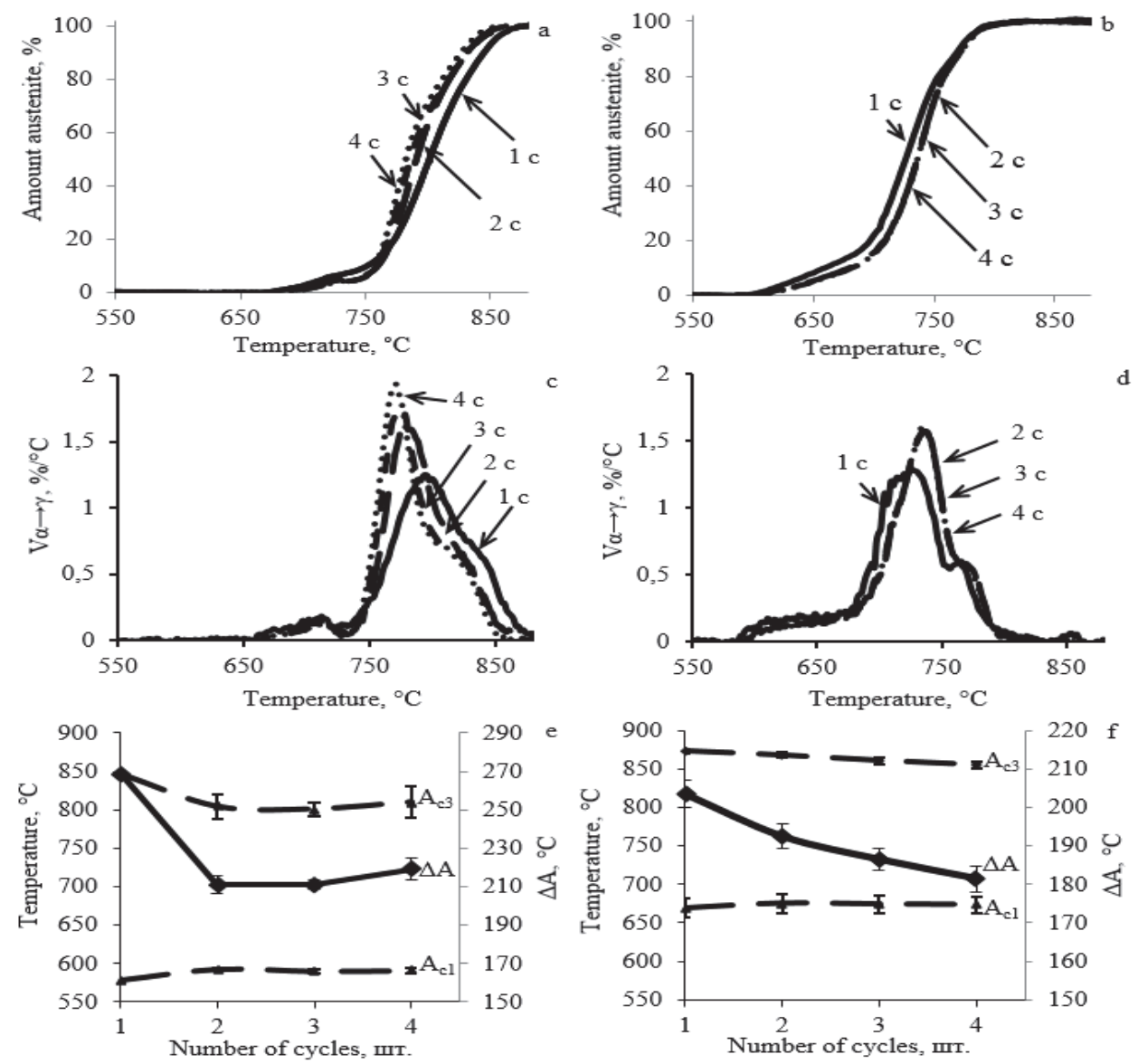

Fig. 4. kinetics $(a, b)$ and austenite formation rate $\mathrm{V}_{\alpha \rightarrow \gamma}(c, d)$, position of $\mathrm{A}_{\mathrm{c} 1}$ and $\mathrm{A}_{\mathrm{c} 3}$ critical points and the width of ITR $(\Delta A)(e, f)$ during continuous heating of steel $10 \mathrm{H} 3 \mathrm{G} 3 \mathrm{MF}$ in initially hardened $(a, c, e)$ and initially cold-deformed condition $(b, d, f)$ during TCP at $900{ }^{\circ} \mathrm{C}$ with a heating rate of 90 ${ }^{\circ} \mathrm{C} / \mathrm{c}$

The analysis of the kinetics of austenite formation during TCP of initially hardened analyzed steel showed that from cycle to cycle an increase of rate of $\alpha \rightarrow \gamma$-transformation at heating with a rate of 90 ${ }^{\circ} \mathrm{C} / \mathrm{sec}$ (Fig. 4a, 4c) is observed, which is caused by structure refinement as a result of TCP at $900{ }^{\circ} \mathrm{C}$, and consequently by increase of the number of sites of austenite germs formation during heating. The study of width of inter-critical temperature range (ITR) $(\Delta A)$ showed that, with increasing the rate of $\alpha$ $\rightarrow \gamma$-transformation $\Delta A$ is narrowed (Fig. 4e). 
The kinetics of austenite formation under continuous heating during TCP at $900{ }^{\circ} \mathrm{C}$ of initially cold-deformed studied steel indicates the greatest rate of the austenite formation in ITR at the 2-nd, 3$\mathrm{d}$ and 4-th heating cycle, which is provided by the dispersion of the structure at the first cycle (Fig. 4b, 4d) and at the second and the following cycles the dispersed hardened condition is exposed to heating. It should be noted that the austenite formation kinetic curves at the 2, 3 and 4-th heating cycles during TCP superimpose on one another, which indicates the common character of the $\alpha \rightarrow \gamma$-transformation, and as a result, the close realized structure on these processing cycles. The width of ITR $(\triangle A)$ at TCP of the initially cold-deformed steel decreases in the second cycle of austenization and remains practically unchanged at the following cycles (Fig. 4f).

Then the profile of the first derivative of dilatometric curves of heating was resolve into components during high speed TCP on the components peaks (Fig. 5).
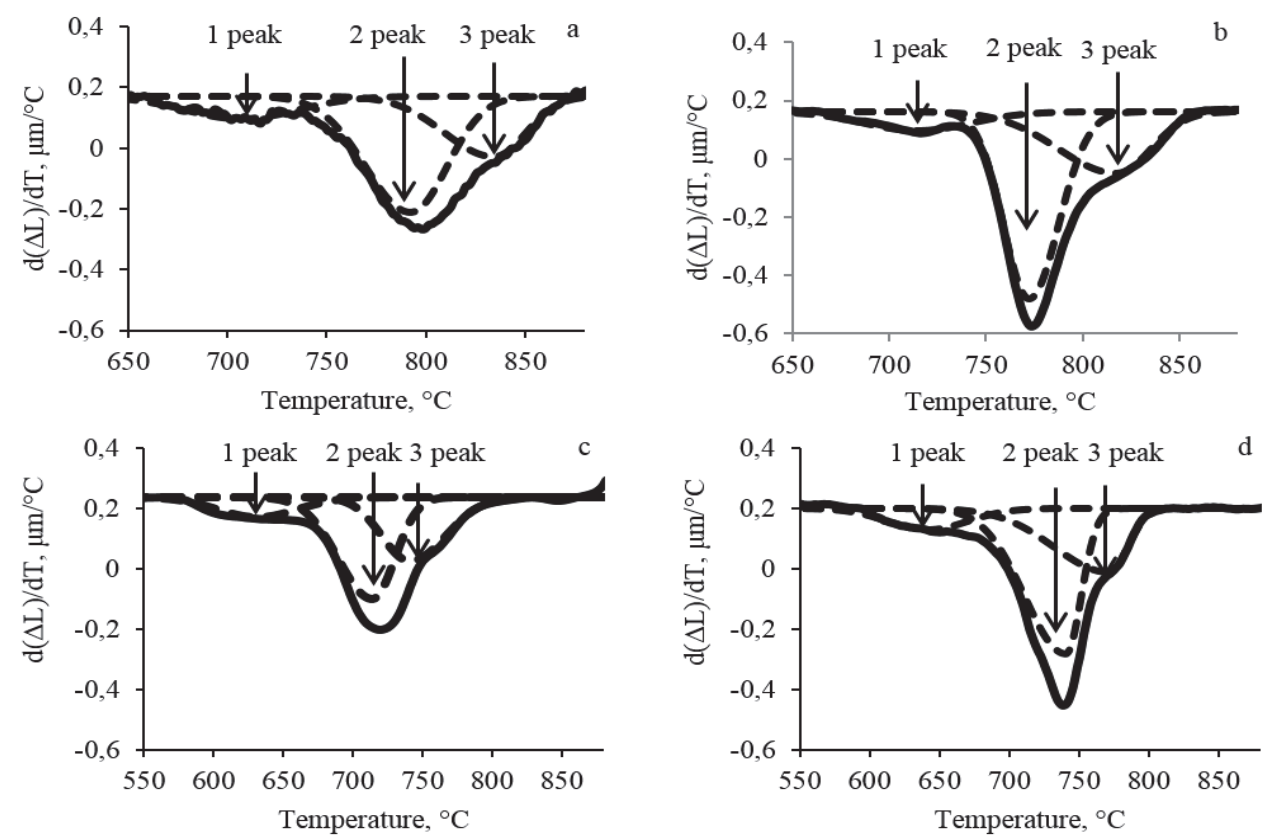

Fig. 5. Resolving into peaks of the profile of the first derivative of dilatometric curves of the continuous heating during high speed TCP at $900{ }^{\circ} \mathrm{C}$ of steel $10 \mathrm{H} 3 \mathrm{G} 3 \mathrm{MF}$ in initially hardened (a, b) and initially cold-deformed condition (c, d): a, c -1 cycle; $b, d-4$ cycle

At all studied modes of high speed TCP of steel 10H3G3MF three phases of $\alpha \rightarrow \gamma$-transformation are observed. Dependences of the position of the maximum of peaks on the number of cycles of the high speed TCP at $900{ }^{\circ} \mathrm{C}$ of the studied steel in initially hardened and initially cold-deformed condition are presented in Fig. 6 . According to previous studies in the first phase of the $\alpha \rightarrow \gamma$-transformation of the analyzed steel in the initially hardened condition austenite is formed on the borders of the former austenite grains, which called the "grain-border effect" in the work of Sadowski (1973). The process of formation and growth of austenite germs on the between-sticks borders of martensite acts as a second phase of transformation, which is provided by the greatest diffusion mobility of atoms of carbon and iron in these elements of the substructure (Dillon et al. 2007). Such character of austenite formation on between-sticks borders of martensite was investigated in the works of Schastlivtsev and Koptseva (1976) and Zeldovich (2008). The third phase consists in the growth of the austenite germs on betweenstick border in the body of elements of structure and substructure, in this case - the martensite sticks. There are a lot of works (e.g. Tokizane et al. (1982), Chang \& Yu 2013, Wei et al. 2013, Huang et al. 2004, Bojack et al. 2012) where staging of the $\alpha \rightarrow \gamma$-transformation is emphasized, but separation of temperature intervals of three different stages of austenite formation on the basis of volume effects has been done in this work for the first time. As for the steel in initially cold-deformed condition at the first 
processing cycle, in the first phase the $\alpha \rightarrow \gamma$-transformation develops along the border of polygons, in a second phase - along the borders of recrystallized grains, in the third phase - in the volume of recrystallized grains. On the second and the following cycles of processing the studied steel in the hardened condition is exposed to heating.

The shares in the total volume effects on the 1,2 and 3 phases of transformation for the initially hardened and initially cold-deformed condition are nearly the same and with increase of the number of cycles are practically unchanged. $11-12 \%$ of volume effect of $\alpha \rightarrow \gamma$-transformation fall on the first phase $\alpha \rightarrow \gamma$-conversion, 56-57\% of volume effect of $\alpha \rightarrow \gamma$-transformation - on the second phase, 30$32 \%$ volume effect of $\alpha \rightarrow \gamma$-transformation - on the third phase.

During high speed TCP of the analyzed steel in the initially hardened condition the tendency to decrease of the peak positions of 2 and 3 phases of $\alpha \rightarrow \gamma$-transformation in the temperature scale is observed, and the peak position of the 1 phase during TCP remains unchanged (Fig. 6a). This is the reason of increase of the intensity of the $\alpha \rightarrow \gamma$-transformation (Fig. 4a) as a result of structure dispersing from cycle to cycle, which leads to the development of the respective transformation stages at lower temperatures.
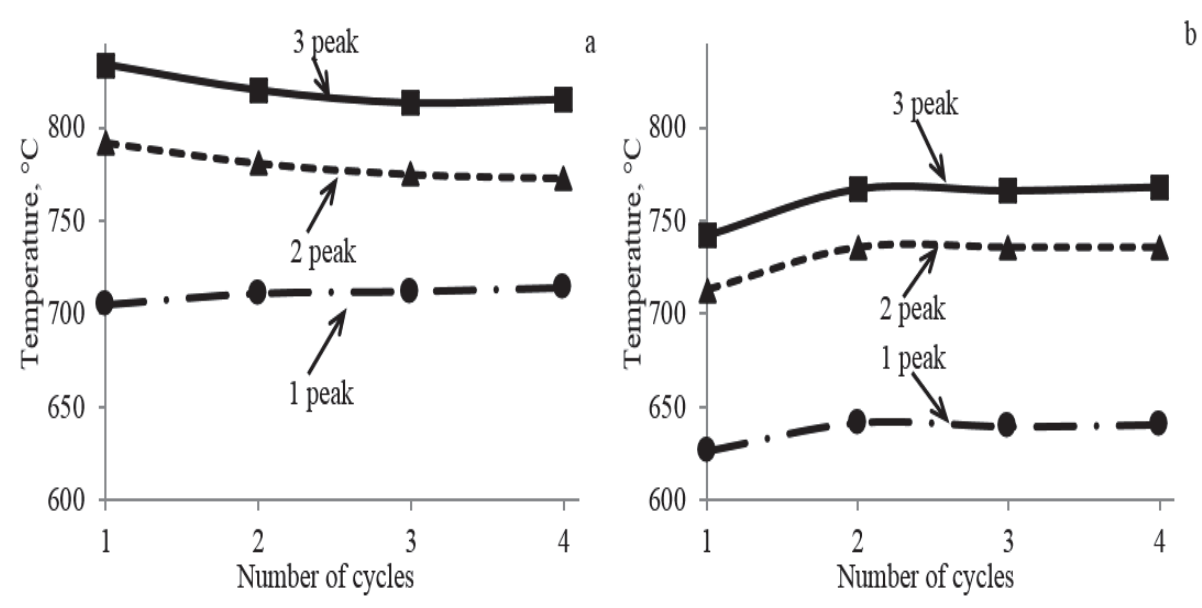

Fig. 6. Dependences of the positions of peak temperatures on each cycle of TCP at $900{ }^{\circ} \mathrm{C}$ of steel 10H3G3MF in initially hardened (a) and initially cold-deformed (b) condition

The temperatures of the peaks in the high speed TCP of the studied steel in initially cold-deformed condition at the first cycle is lower than at the second cycle where they are raised upwards along the temperature axis, and remain unchanged with increasing of a number of cycles (Fig. 6b). This is due to the lower position of the critical temperature $A_{c 1}$ in the first cycle and its following increase during high speed TCP, which causes the development of all phases of $\alpha \rightarrow \gamma$-transformation at lower temperatures due to the defective initial condition.

\subsection{Study of characteristics of mechanical properties}

The results of the study of characteristics of mechanical properties of steel 10H3G3MF in initially hardened and initially cold-deformed condition after different modes of high-speed TCP are given in Table 1. High speed TCP at $900{ }^{\circ} \mathrm{C}$ of the analyzed steel in initially hardened condition on the first heating cycle causes an increase in the flow limit $\left(\sigma_{0,2}\right)$ of steel by about $20 \%$, and a tensile strength $\left(\sigma_{b}\right)$ and the characteristics of plasticity $(\delta, \psi)$ vary a little (Table 1$)$. Increase of the number of cycles at $900{ }^{\circ} \mathrm{C}$ to three leads to increase of the flow limit $\left(\sigma_{0,2}\right)$ to the level of $1100 \mathrm{MPa}$, which exceeds the level of this characteristics approximately by $25 \%$ in the initially hardened condition. Tensile strength $\left(\sigma_{\mathrm{b}}\right)$, relative elongation $(\delta)$ and the relative reduction $(\psi)$ also remain at the same level. After increasing 
the number of cycles of the high speed TCP to five at $900{ }^{\circ} \mathrm{C}$ the level of characteristics of strength and plasticity of the analyzed steel remains practically unchanged. Such character of changes of the mechanical properties during high speed TCP at $900{ }^{\circ} \mathrm{C}$ is provided by dispersion of austenite grains to the third cycle of processing and its stabilization on the subsequent cycles, which in accordance with the Hall-Petch law (Hall 1951, Petch 1953), leads to increase in the flow limit $\left(\sigma_{0,2}\right)$ in the first three cycles of processing. High speed TCP at $1000^{\circ} \mathrm{C}$ in the first cycle causes an increase in flow limit $\left(\sigma_{0,2}\right)$ by $5 \%$ at constant tensile strength $\left(\sigma_{b}\right)$ and characteristics of plasticity $(\delta, \psi)$. When number of cycles is increased to three the flow limit $\left(\sigma_{0,2}\right)$ is increased by $10 \%$ relative to the initially hardened condition, while the other characteristics remain the same. The following increase in the number of processing cycles to 5 does not significantly change the mechanical properties.

Table 1. The properties of the steel 10H3G3MF after different modes of high speed TCP

\begin{tabular}{llllll}
\hline Processing mode & $\sigma_{0,2}$, & $\sigma_{\mathrm{b}}$, & $\begin{array}{l}\delta, \\
\%\end{array}$ & $\begin{array}{l}\psi, \\
\%\end{array}$ & $\begin{array}{l}\mathrm{SSC}, \\
\mathrm{MJ} / \mathrm{m}^{2}\end{array}$ \\
\hline Initially hardened condition & 890 & 1290 & 16 & 63 & 0.21 \\
High speed TCP at $900^{\circ} \mathrm{C}, 1$ cycle. & 1060 & 1300 & 17 & 65 & 0.34 \\
High speed TCP at $900^{\circ} \mathrm{C}, 3$ cycle. & 1100 & 1330 & 17 & 61 & 0.66 \\
High speed TCP at $900^{\circ} \mathrm{C}, 5$ cycle. & 1080 & 1320 & 18 & 66 & 0.68 \\
High speed TCP at $1000^{\circ} \mathrm{C}, 1$ cycle. & 940 & 1290 & 17 & 65 & 0.40 \\
High speed TCP at $1000^{\circ} \mathrm{C}, 3$ cycle. & 1000 & 1270 & 17 & 66 & 0.40 \\
High speed TCP at $1000^{\circ} \mathrm{C}, 5$ cycle. & 990 & 1280 & 17 & 65 & 0.47 \\
Initially cold-deformed condition & - & 1780 & 7 & 53 & 0.55 \\
ZAK $+\mathrm{HPD} 60 \%+$ one-time heating by $900^{\circ} \mathrm{C}$ & 1360 & 1420 & 13 & 69 & 0.91 \\
ZAK $+\mathrm{HPD} 60 \%+$ one-time heating by $1000^{\circ} \mathrm{C}$ & 1100 & 1310 & 14 & 69 & 1.15 \\
\hline
\end{tabular}

As analysis of mechanical properties of the steel 10H3G3MF in initially cold-deformed condition showed, that the flow limit $\left(\sigma_{b}\right)$ is higher with respect to the initially hardened condition with the hot forging temperature by $40 \%$, but at the same time the decrease in relative elongation $(\delta)$ more than two times and the relative reduction $\psi$ by $16 \%$ is observed. The flow limit in such condition of steel is not physically realized, because the tensile strength is reached earlier than relative deformation of $0.2 \%$.

After one cycle of fast heating by $900{ }^{\circ} \mathrm{C}$ of the studied steel in initially cold-deformed condition as a result of obtaining of the nano-structural condition (Fig. 2c) plasticity and toughness are significantly increased. At the same time high values of the flow limit remain unchanged (more than $50 \%$ higher than initial hardened condition) and tensile strength (by $10 \%$ higher than initial hardened condition). One-time heating of steel $10 \mathrm{H} 3 \mathrm{G} 3 \mathrm{MF}$ by $1000^{\circ} \mathrm{C}$ in initially cold-deformed condition leads to the lower values of strength characteristics which is caused by the formation of larger structures (Fig. $1 b)$.

Micro-fractographic analysis of fracture of the steel 10H3G3MF in initially hardened condition with hot forging temperatures in the area of destruction, where plain-deformed condition is realized, showed that the main element of the fracture structure is a facet of quasi-spalling (Fig. 7a).

Impact hardness (SSC) of the analyzed steel in the initially hardened condition, after one cycle of the high speed TCP at $900{ }^{\circ} \mathrm{C}$ is increased by 1.5 times (Table 1). Increase of the number of cycles at $900{ }^{\circ} \mathrm{C}$ to 3 causes a further increase of the toughness (SSC) to $0.66 \mathrm{MJ} / \mathrm{m}^{2}$, that is 3 times higher compared to initial condition (Table 1). In the microstructure of the fracture after this type of processing, signs of ductile fracture - pits appear to a greater extent (Fig. 7b). Increase of the number of processing cycles at $900{ }^{\circ} \mathrm{C}$ to five does not cause the change of the level of toughness (SSC) of the analyzed steel (Table 1). After high speed TCP at $1000{ }^{\circ} \mathrm{C}$ on the first cycle SSC impact hardness increases 2 times. Further increase of a number of cycles up to 5 at $1000{ }^{\circ} \mathrm{C}$ of steel $10 \mathrm{H} 3 \mathrm{G} 3 \mathrm{MF}$ in the initially hardened condition does not cause increase in impact hardness (SSC value in Table 1). 


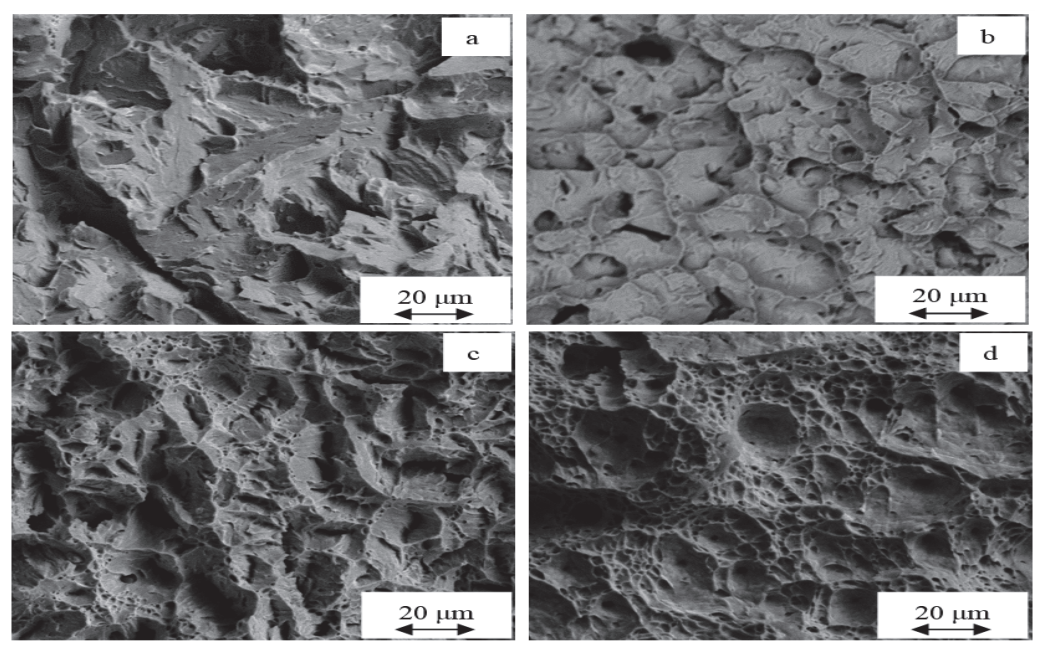

Fig. 7. Microstructure of fractures of the $10 \mathrm{H} 3 \mathrm{G} 3 \mathrm{MF}$ steel in initially hardened condition (a), after three cycles of the high speed TCP at $900{ }^{\circ} \mathrm{C}$ in the initially hardened condition (b), in the colddeformed condition (c), after one cycle of processing at $900{ }^{\circ} \mathrm{C}$ in an initially cold-deformed condition (d) of tests in SSC.

Impact hardness (SSC) of the studied steel in the initially cold-deformed condition increased more than 2.5 times relative to the steel in the initially hardened condition (Table 1), it is caused by complication of the trajectory of development of a crack at fracture due to the discontinuity of the product properties on the cross section, resulting from a radial cold forging. The destruction of the analyzed steel in the initially cold-deformed condition occurs according to the viscous micromechanism with formation of pits in the microstructure of the fracture (Fig. 7c). Impact hardness (SSC) after a single heating to $900{ }^{\circ} \mathrm{C}$ of the analyzed steel in the initially cold-deformed condition increases more than 4 times as compared to the steel in the initially hardened condition (Table 1). The microstructure of the fracture surface consists of pits and cones pits (Fig. 7d), i.e., change of micromechanism of fracture from quasi-spalling to viscous during the transition to nanostructured condition. The values of impact hardness (SSC) after one cycle of heating to $1000{ }^{\circ} \mathrm{C}$ are the high, but close to the level of the same steel after one time heating by $900^{\circ} \mathrm{C}$ (Table 1$)$.

\section{Conclusion}

The performed studies demonstrated that high speed TCP at $900{ }^{\circ} \mathrm{C}$ of the analyzed steel $10 \mathrm{H} 3 \mathrm{G} 3 \mathrm{MF}$ in initially hardened condition causes austenite grain refinement, occurs to the third heating cycle, at the same time austenite grain structure with an average size of about $2 \mu \mathrm{m}$ is formed, and with increase of the number of processing cycles the grain remains practically unchanged. Most fine crushing of the austenite grain structure of initially cold-deformed steel occurs at the first cycle of heating to $900{ }^{\circ} \mathrm{C}$, which crushes austenite grains to $1 \mu \mathrm{m}$, and upon further cycling the austenite grain growth up to the third cycle is observed, followed by stabilization at the level of $3.5 \mu \mathrm{m}$. High speed TCP at $1000{ }^{\circ} \mathrm{C}$ after all studied modes leads to preparation of the austenite grain with an average size at a level of $6-8 \mu \mathrm{m}$. Study by methods of transmission electron microscopy of steel 10H3G3MF after various modes of high speed TCP established that after 3 cycles at $900{ }^{\circ} \mathrm{C}$ of initially hardened steel the massive martensite structure with an average cross sectional dimension of stick in the plane of foil is $120 \pm 10 \mathrm{~nm}$, and in the case of one heating cycle to $900{ }^{\circ} \mathrm{C}$ of initially cold-deformed steel the nanostructured condition of massive martensite is realized with an average size of the stick in the plane of foil equal to $60 \pm 10 \mathrm{~nm}$.

Dilatometric analysis of the processes of the high speed TCP at $900{ }^{\circ} \mathrm{C}$ showed that in the process of dispersing structure ITR of steel $10 \mathrm{H} 3 \mathrm{G} 3 \mathrm{MF}$ in initially hardened and initially cold-deformed 
condition is narrowed because of increasing the rate of $\alpha \rightarrow \gamma$-transformation. At the studied modes of the high speed TCP of steel 10H3G3MF three phases of $\alpha \rightarrow \gamma$-transformation in ITR are observed. The share in the total volume effects of the first, second and third phase of $\alpha \rightarrow \gamma$-transformation in ITR from cycle to cycle studied steel does not depend on the number of cycles of processing and the initial condition: $11-12 \%$ volume effect of $\alpha \rightarrow \gamma$ - transformation fall within the first phase, 56-57\% within the second phase, $30-32 \%$ - within the third phase.

The highest complex of mechanical properties of steel 10H3G3MF in initially hardened condition has been obtained as a result of 3 cycles of the high speed TCP at $900{ }^{\circ} \mathrm{C}$, at the same time there is an increase of the flow limit $\left(\sigma_{0,2}\right)$ to the level of $1100 \mathrm{MPa}$, which is $25 \%$ higher than the level of this characteristics in the initially hardened condition, tensile strength $\left(\sigma_{B}\right)$, the relative elongation $(\delta)$, and the relative reduction $(\psi)$ also remain at the same level, and the level of impact hardness (SSC) is increased 3 times compared with initial condition to $0.66 \mathrm{MJ} / \mathrm{m}^{2}$. As for the studied steel in initially cold-deformed condition the highest complex of mechanical properties is realized after one cycle of fast heating to $900{ }^{\circ} \mathrm{C}$ as a result of a nanocrystalline condition -the value of the flow limit is 1360 $\mathrm{MPa}$ and tensile strength is $1420 \mathrm{MPa}$, which is higher than the initially hardened condition by more than $50 \%$ and $10 \%$, respectively, and impact hardness (SSC) is increased to $0.91 \mathrm{MJ} / \mathrm{m}^{2}$, i.e. four times higher than the hardened condition. Increase of the number of cycles or temperature of heating does not lead to a significant change in the properties, or does not cause their reduction.

Proposed in the article mode of hardening treatment can be used to produce high strength and high reliability long fasteners from the steel $10 \mathrm{H} 3 \mathrm{G} 3 \mathrm{MF}$ as used processing methods (radial forging and heat treatment in a salt bath) allow to produce cylindrical bar stock. As further research directions serial tests are planned to determine cold-shortness threshold of steel $10 \mathrm{H} 3 \mathrm{G} 3 \mathrm{MF}$ in different structural conditions obtained in this work. It is prospective to study the opportunities of hardening investigated steel by speed thermal treatment in the inter-critical temperature range.

\section{References}

Bojack, A., Zhao, L., Morris, P. F., \& Sietsma, J. (2012). In-situ determination of austenite and martensite formation in $13 \mathrm{Cr} 6 \mathrm{Ni} 2 \mathrm{Mo}$ supermartensitic stainless steel. Materials Characterization, 71, 77-86.

Chang, M., \& Yu, H. (2013). Kinetics of bainite-to-austenite transformation during continuous reheating in low carbon microalloyed steel. International Journal of Minerals, Metallurgy, and Materials, 20(5), 427-432.

Dillon, S. J., Tang, M., Carter, W. C., \& Harmer, M. P. (2007). Complexion: A new concept for kinetic engineering in materials science. Acta Materialia,55(18), 6208-6218.

Gladstein, L.I., Rivanenok, T.N., \& Christov, A.V. (2008). Dilatometric analysis of the kinetics of polymorphic transformation during heating of steel. Plant Laboratory. Diagnosis of materials, 6, 3639.

Hall, E. O. (1951). The deformation and ageing of mild steel: III discussion of results. Proceedings of the Physical Society. Section B, 64(9), 747.

Huang, J., Poole, W. J., \& Militzer, M. (2004). Austenite formation during intercritical annealing. Metallurgical and Materials Transactions A, 35(11), 3363-3375.

Kaputkin, D.E. (2007). Nonequilibrium conditions of structure of hardened multicomponent alloys of iron and their approach to equilibrium. Fundamental problems of modern metallurgy, 4(1), 58-65.

Kurdyumov, G. V., Utevskii, L. M., \& Entin, R. I. (1977). Transformations in iron and steel.

Lee, S. J., \& Lee, Y. K. (2008). Prediction of austenite grain growth during austenitization of low alloy steels. Materials \& Design, 29(9), 1840-1844.

Linxiu, D. U., Shengjie, Y. A. O., Xianghua, L. I. U., \& Guodong, W. A. N. G. (2009). Growth behavior of ultrafine austenite grains in microalloyed steel. Acta Metallurgica Sinica (English Letters), 22(1), $7-12$. 
Panov, D.O., Balakhnin, A.N., Titova, M.G., Orlova, E.N., Smirnov, A.I., \& Simonov, Y.N. (2012). Evolution of the structure and properties at intensive thermal-cycle processing of cold-deformed hardened systemically alloyed steel 10H3G3MF. Metallurgy and heat treatment of metals, 11, 1722.

Petch, N. J. (1953). The cleavage strength of polycrystals. Journal of Iron Steel Industries, 174, 25-28. Sadowski,,V.D. (1973). Structural heredity in steel. Metallurgy, Moscow.

Schastlivtsev, V.M. \& Koptseva, N.V. (1976). Electron microscopic studies of austenite during heating of constructional steel. The Physics of Metals and Metallography, 42(4), 837 - 847.

Segal, V.M. (1994). Plastic structure formation processes of metals. Science and Technology, Minsk. Simonov, Y.N., Panov, D.O., Simonov, M.Y., Kasatkin, A.V. \& Poduzov, D.P. (2013). Low-carbon alloy steel. Patent 2477333 Russian Federation.

Tokizane, M., Matsumura, N., Tsuzaki, K., Maki, T., \& Tamura, I. (1982). Recrystallization and formation of austenite in deformed lath martensitic structure of low carbon steels. Metallurgical and Materials Transactions A,13(8), 1379-1388.

Tyurin, V.A., Lazorkin, V.A. \& Pospelov I.A. (1990). Forging on radial crimping machines. Mechanical Engineering, Moscow.

Valiev, R.Z. (2006) .Creation of nanostructured materials and alloys with unique properties using severe plastic deformations. Russian Nanotechnology. 1-2, 208-215.

Wei, R., Enomoto, M., Hadian, R., Zurob, H. S., \& Purdy, G. R. (2013). Growth of austenite from asquenched martensite during intercritical annealing in an $\mathrm{Fe}-0.1 \mathrm{C}-3 \mathrm{Mn}-1.5 \mathrm{Si}$ alloy. Acta Materialia, 61(2), 697-707.

Zel'dovich, V. I. (2008). Three mechanisms of formation of austenite and inheritance of structure in iron alloys. Metal Science and Heat Treatment, 50(9-10), 442-448. 